\title{
Modelling the shear edge eddies of the southern Agulhas Current
}

\author{
J.R.E. Lutjeharms ${ }^{\mathrm{a}}$, P. Penven ${ }^{\mathrm{a}, \mathrm{b}, \mathrm{c}, *}$, C. Roy ${ }^{\mathrm{a}, \mathrm{b}}$ \\ a Department of Oceanography, University of Cape Town, 7700 Rondebosch, South Africa \\ ${ }^{\mathrm{b}}$ Institut de Recherche pour le Développement, 213 rue Lafayette, Paris, France \\ ${ }^{\mathrm{c}}$ Laboratoire de Physique des Océans, Université de Bretagne Occidentale/UFR Sciences, 6 avenue Le Gorgeu-BP809, \\ 29285 Brest cedex, France
}

Received 30 September 2002; accepted 7 May 2003

\begin{abstract}
Observations have revealed the presence of cyclonic eddies embedded in the landward border of the southern Agulhas Current. These shear edge eddies are most prevalent in the Agulhas Bank shelf bight, have a diameter of about 50$100 \mathrm{~km}$ and are represented by a thermal dome and a surface warm plume inshore. In an attempt to better understand their generation and behavior, we have used a high-resolution model designed for the general region. The ocean model employed is the Regional Ocean Modeling System that solves the free surface, hydrostatic, primitive equations over variable topography using stretched, terrain-following coordinates in the vertical, orthogonal curvilinear coordinates in the horizontal, and featuring high-order schemes. The model simulates the creation of cyclonic shear edge eddies and their attendant surface plumes of warm water along the edge of the Agulhas Bank with a high degree of verisimilitude. The dimensions of the model features, their hydrographic structure and their velocities bear a strong resemblance to what has been observed. The simulation suggests that shear edge eddies remain trapped in the Agulhas Bank shelf bight and that eddies that subsequently travel downstream represent leakages from the resident shear eddy. This intermittent but frequent leakage of cyclonic motion downstream propagates at roughly $8 \mathrm{~km} \mathrm{day}^{-1}$ at intervals of roughly 20 days, and may trigger the detachment of a cyclonic eddy at the tip of the Agulhas Bank.
\end{abstract}

(C) 2003 Elsevier Ltd. All rights reserved.

Keywords: Agulhas current; Bottom topography effects; Boundary currents; Ocean models; Oceanic eddies; Shear edge eddies, Regional index terms: South Africa; Agulhas Bank; Agulhas Bank Shelf Bight Geographic bounding coordinates: $34^{\circ} \mathrm{S}-38^{\circ} \mathrm{S} ; 1^{\circ} \mathrm{E}-25^{\circ} \mathrm{E}$

\section{Introduction}

The southern and the northern parts of the Agulhas Current exhibit consistent differences in

\footnotetext{
*Corresponding author. Laboratoire de Physique des Océans, Faculté des Sciences, Av. V. Le Gorgeu, Brest 29287, France.

E-mail address: penven@univ-brest.fr (P. Penven).
}

their path characteristics to an extent that may allow a nomenclatural distinction between the southern Agulhas Current and the northern Agulhas Current. Whereas the trajectory of the northern Agulhas is unusually stable for a western boundary current (Gründlingh, 1983), the southern Agulhas has large meanders (Harris et al., 1978; Lutjeharms, 1981). This contrasting kinematic behavior is a consequence of the steepness of 
the continental shelf slope (De Ruijter et al., 1999). A very steep slope and narrow continental slope constrains the northern part of the current whereas a more gradual slope along the wider continental shelf south of Africa (the Agulhas Bank) allows more side-ways meandering. The exception is a small region of weaker slope along the northern Agulhas Current, at the Natal Bight, where small meanders and accompanying eddies have also been observed (Gründlingh and Pearce, 1990) along the edge of the current. Cyclonic eddies are embedded in the landward border of current meanders in the southern Agulhas Current and seem to gain energy from the lateral shear due to the juxtaposition of fast moving water in the current and more sluggish water over the shelf.

These cyclonic shear eddies may have a substantial influence on adjacent shelf waters of the Agulhas Bank. They are usually attended by warm plumes drawn from the surface waters of the current (Harris et al., 1978; Lutjeharms, 1981; Schumann and van Heerden, 1988; Lutjeharms et al., 1989; Goschen and Schumann, 1990). These plumes have in fact been the prime manifestation of shear edge eddies and has been used for their study by thermal infrared images from satellite. Depending on the wind conditions, this anomalously warm surface water may then spread over substantial parts of the adjacent shelf (Lutjeharms et al., 1989; Goschen and Schumann, 1994). It has even been surmised (Swart and Largier, 1987) that this warm surface water may thus make an important contribution to the intense seasonal thermocline over the eastern part of the Agulhas Bank (Schumann and Beekman, 1984). This hypothesized contribution has as yet not been quantified. Regrettably, few of these shear edge eddies have to date been hydrographically surveyed. For the purpose of verifying the model results we use the best - be it old - available data sets.

A study by Lutjeharms et al. (1989) has used two sets of hydrographic observations as well as satellite imagery to give a general description of these features. More eddies are found the further downstream one measures. In general their lateral dimensions also increase downstream. They seem to be particularly prevalent in the shelf bight on the eastern side of the Agulhas Bank. Judged by the trailing plumes of warm water, they all move downstream, but an insufficient number of time series in the satellite imagery has prevented a statistically reliable propagation speed to be derived. Once past the southern tip of the Agulhas Bank, warm plumes may be advected equatorward into the southern Atlantic Ocean, making a modest contribution to the inter-ocean leakage of heat and salt (Lutjeharms and Cooper, 1996). The fate of the eddies themselves remains largely unknown. Lagrangian observations (Lutjeharms et al., 2003) have shown that some shear edge eddies that move downstream may spin off the southern tip of the Agulhas Bank and move into the South Atlantic as independent Agulhas cyclones. Shear edge eddies may have a diameter of about $50-100 \mathrm{~km}$ and are represented by a welldefined thermal dome (Lutjeharms et al., 1989) inshore of the landward border of the Agulhas Current. This portrayal of these eddies is complicated by the intermittent passage of a Natal Pulse through the region.

Natal Pulses are substantial, single meanders in the trajectory of the Agulhas Current (Lutjeharms and Roberts, 1988) that are generated by current instability at the Natal Bight (De Ruijter et al., 1999) and that propagate downstream at a rate of about $20-30 \mathrm{~km} \mathrm{day}^{-1}$. When they move past the Agulhas Bank, they seem to slow down to roughly $5 \mathrm{~km} \mathrm{day}^{-1}$ (Lutjeharms and Roberts, 1988; Van Leeuwen et al., 2000) and become difficult to distinguish from the other meanders normally found here. Like these other meanders, Natal Pulses also incorporate cyclonic eddies (Gründlingh, 1979) that move downstream with them. Once past the southernmost tip of the Agulhas Bank, Natal Pulses may trigger the shedding of an Agulhas ring (Van Leeuwen et al., 2000; Lutjeharms et al., 2003) by loop occlusion at the Agulhas retroflection (Lutjeharms and van Ballegooyen, 1988). The role that this process plays in interocean exchanges South of Africa has been extensively reviewed by De Ruijter et al. (1999) and Lutjeharms (1996). Float trajectories have suggested (Lutjeharms et al., 2003) that cyclones carried in a Natal pulse drift off into the South Atlantic once the meander has passed the tip of the 
Agulhas Bank. There is evidence that a cyclonic eddy may on occasion be generated in the lee (western side) of the Agulhas Bank by passing the Agulhas Current (Penven et al., 2001) and it has been surmised that the cyclonic eddy that comes with a Natal Pulse may be absorbed by such a lee eddy. Similarly, it has been hypothesized that shear edge eddies may be absorbed by this same lee eddy, thus enhancing it and expediting its shedding. In an attempt to test this latter hypothesis and to understand the processes involved in the generation and subsequent behavior of shear edge eddies, we have used a high-resolution model for the region. Since in this investigation we wish to focus on the behaviour of true shear edge eddies, the model does not accommodate the effect of upstream perturbations, such as Natal Pulses.

\section{Model characteristics}

The ocean model used is the Regional Ocean Modeling System (ROMS) (Haidvogel et al., 2000; Shchepetkin and McWilliams, unpublished). It solves the free surface, primitive equations in an Earth-centered rotating environment, based on the Boussinesq approximation and hydrostatic vertical momentum balance. ROMS is discretized in coastline- and terrain-following curvilinear coordinates.

The third-order, upstream-biased advection scheme implemented in ROMS allows the generation of steep gradients, enhancing the effective resolution of the solution for a given grid size (Shchepetkin and McWilliams, 1998). Explicit lateral viscosity is null everywhere in the model domain except in sponge layers near the open boundaries where it increases smoothly in the 6 points close to the lateral open boundaries to attain a value of $800 \mathrm{~m} \mathrm{~s}^{-2}$.

A non-local, K-profile planetary (KPP) boundary layer scheme (Large et al., 1994) parameterizes the unresolved physical vertical subgrid-scale processes.

To minimize the number of masked points that are dead point in computing the solution, the curvilinear grid has been built following an arc of a circle (Fig. 1). It follows the south-western corner of the African continent from $40^{\circ} \mathrm{S}$ to $28^{\circ} \mathrm{S}$ and from $10^{\circ} \mathrm{E}$ to $24^{\circ} \mathrm{E}$. Hence, the model domain includes all the south and south-west coasts of South Africa from Lüderitz to the north and to Cape St. Francis in the south-east. The resolution is a minimum $(9 \mathrm{~km})$ at the coast where we need a more accurate solution and linearly increases with off-shore distance to reach a maximum of $16 \mathrm{~km}$. The first baroclinic Rossby radius of deformation is resolved everywhere. The grid is isotropic and thus does not produce any asymmetry in the horizontal dissipation of turbulence.

Twenty vertical levels preserve a high resolution near the surface. The bottom topography is derived from a 2 min resolution database (Smith and Sandwell, 1997). The bathymetry has been filtered in order to obtain a "slope parameter" $r=\nabla h / h<0.15$ (see Haidvogel et al., 2000), preventing errors in the computation of the pressure gradient. The vertical resolution is ranging from 1 to $4.7 \mathrm{~m}$ at the surface and from 3.1 to $1030 \mathrm{~m}$ at the bottom.

The model is forced by winds, heat fluxes and fresh water fluxes derived from the COADS ocean surface monthly climatology at $0.5^{\circ}$ resolution (Da Silva et al., 1994).

At the three lateral boundaries facing the open ocean, an active, implicit, upstream biased, radiation condition connects the model solution to the surroundings (Marchesiello et al., 2001). In the case of inflow conditions, the solution at the boundary is nudged towards cyclic seasonal, timeaveraged outputs of the Agulhas As Primitive Equations (AGAPE) basin scale ocean model (Biastoch and Krauß, 1999), thus explicitly excluding intermittent perturbations from upstream such as Natal Pulses. We have completed the set of open boundaries by introducing a condition for the depth-integrated transport originally proposed by Flather for tidal models (Flather, 1976); this proved to handle the highly energetic and meandering Agulhas Current - that flows westward in the southeast corner of the domain - in a more robust manner.

The summer values of the AGAPE climatology are used for the initial conditions. The domain being relatively small, the solution, starting from rest, quickly adjusts to the initial stratification and 


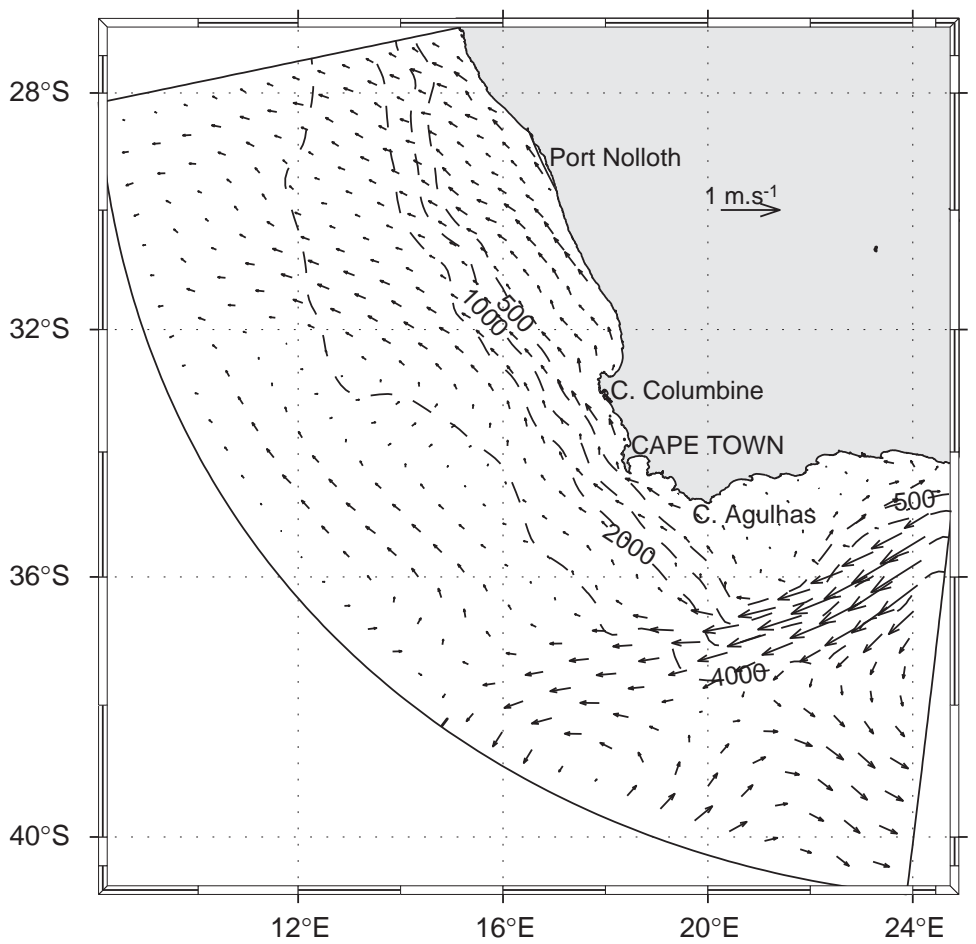

Fig. 1. The pie shaped grid of the model. The vectors represent the surface currents averaged from year 2 to year 10 ( 1 vector every 4 grid points). The dashed lines indicate the topography.

the model reaches a statistical equilibrium after a spin-up of about $1-2$ years. The simulated surface currents, averaged from year 2 to year 10 (Fig. 1), compare well with the measured circulation in the general shelf region (Boyd and Shillington, 1994; Boyd and Oberholster, 1994).

\section{Simulation of the shear edge features}

The sea surface temperature over the Agulhas Bank for 10 April of model year 9 is given in Fig. 2. Simulated surface currents are also shown. Temperatures in the core of the Agulhas Current are $23^{\circ} \mathrm{C}$ and $24^{\circ} \mathrm{C}$ and decrease downstream. Temperatures on the shelf lie between $18^{\circ} \mathrm{C}$ and $20^{\circ} \mathrm{C}$. These values are all very representative for these features for this time of year (Schumann and Beekman, 1984; Lutjeharms, 1996). The core of the simulated Agulhas Current does not follow the shelf edge very rigorously, but overshoots the bight in the Agulhas Bank at about $23^{\circ} \mathrm{E}$, and eventually crosses the $1000 \mathrm{~m}$ isobath at the southernmost tip of the shelf (Fig. 2). Velocities in the core of the current are up to $1 \mathrm{~m} \mathrm{~s}^{-1}$ whereas they are much weaker on the Agulhas Bank $\left(20 \mathrm{~cm} \mathrm{~s}^{-1}\right)$. Both these values are very realistic (Schumann and Perrins, 1982). Two surface plumes of warm water at the inshore edge of the Agulhas Current are evident in Fig. 2. A small plume lies at $20^{\circ} 30^{\prime} \mathrm{E}$, the larger one starts at $22^{\circ} \mathrm{E}$. The latter represents a fully developed shear edge feature around the concave part of the shelf break with surface counter currents of up to $40 \mathrm{~cm} \mathrm{~s}^{-1}$. The implied shear edge eddy has dimensions of approximately $80 \mathrm{~km} \times 150 \mathrm{~km}$. These simulations of the surface characteristics of this region show a high verisimilitude to those evident in Fig. 4a and give a most realistic portrayal of the known conditions for the region, i.e. for this time of the year.

A portrayal of model results for some seasons of model year 7 is given in Fig. 3. Two aspects of the inter-seasonal variability for the sea surface is 


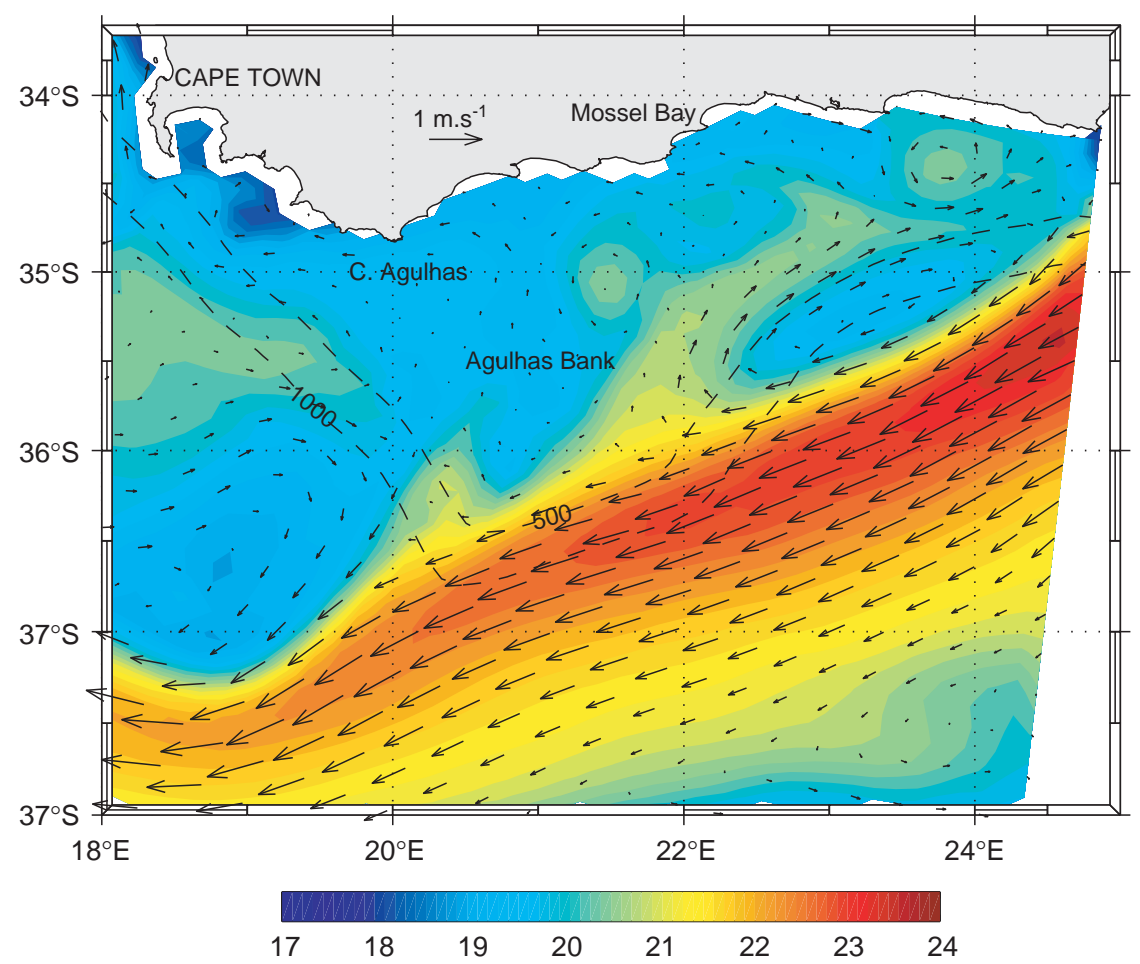

Fig. 2. Sea surface temperature $\left({ }^{\circ} \mathrm{C}\right)$ and surface currents in the southern Agulhas Current and over the Agulhas Bank for 10 April of model year 9. The dashed lines indicate the topography.

immediately apparent. The first is the expected seasonal temperature variations. Both the temperatures in the core of the Agulhas Current and those of the shelf waters exhibit a seasonal cycle of at least $2^{\circ} \mathrm{C}$ (almost $4^{\circ} \mathrm{C}$ near Mossel Bay, $\left.22^{\circ} \mathrm{E}\right)$. These values also are realistic (Christensen, 1980). The second aspect is that the location of the simulated Agulhas Current is not entirely stable. This is particularly noticeable downstream of the Agulhas Bank - from June to October the current shifted by at least $240 \mathrm{~km}$. Along the eastern edge of the Agulhas Bank, the meandering of the Agulhas Current is less noticeable, but inspection of its location at about $23^{\circ} \mathrm{E}$ in June (Fig. 3a) and in October (Fig. 3c) shows a noticeable southward shift. The main shear edge eddy is a recurrent feature of the Agulhas Bank bight, but may lie farther upstream (Fig. 3a) or downstream (Fig. 3d). The simulated surface conditions presented in Figs. 2 and 3 are in accordance with observed patterns.
To judge the full effectiveness of the model, the simulated vertical structure needs to be compared with observations such as those presented in Fig. 4. A vertical section taken from the simulation is shown in Fig. 5. The simulated section in this figure is taken across the eastern Agulhas Bank, across a warm plume, a shear edge eddy as well as the landward edge of the Agulhas Current. The location as well as the time of year has been selected to make comparison easier with the hydrographic section portrayed in Fig. 4b. The main features are well represented in the simulation, including the thermal gradient of the edge of the Agulhas Current, the shape and size of the cold dome representing the eddy as well as the depth and shape of the warm surface plume heading upstream. The plume overlies the landward edge of the eddy, as represented by the strongest horizontal, sub-surface temperature gradient. This corresponds to what has been observed in nature 


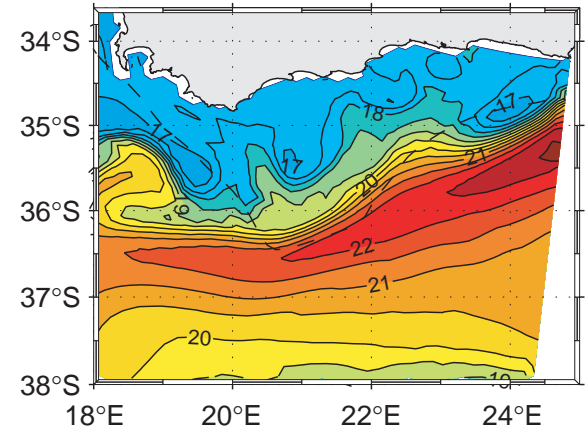

(a)

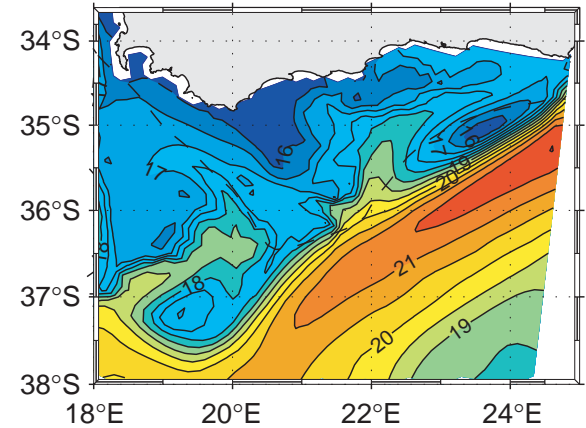

(c)

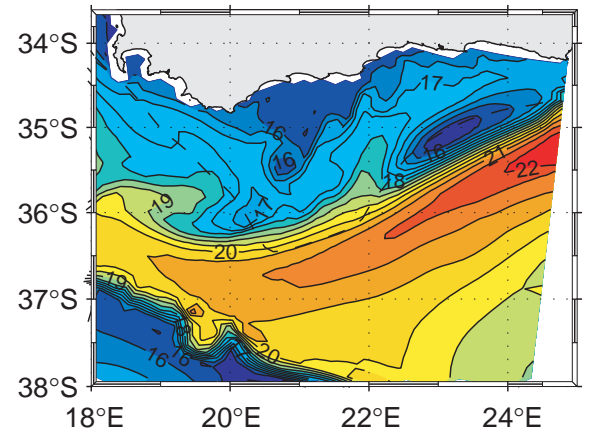

(b)

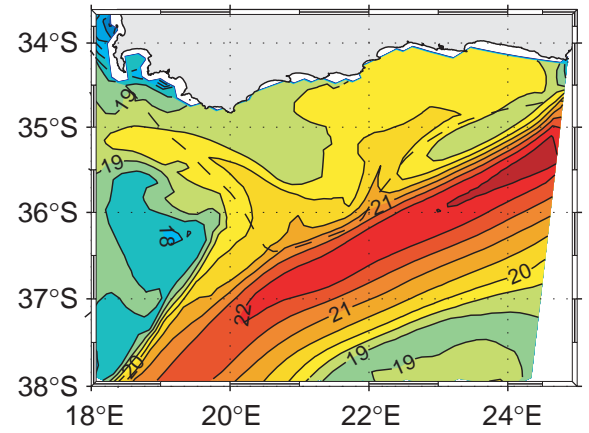

(d)

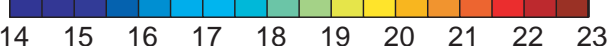

Fig. 3. The simulated sea surface temperature $\left({ }^{\circ} \mathrm{C}\right.$ ) for the Agulhas Bank and direct vicinity for (a) 2 June, (b) 2 August, (c) 2 October and (d) 2 December of model year 7. The interval between the isocontours is $0.5^{\circ} \mathrm{C}$. The broken line represents the $500 \mathrm{~m}$ isobath.

(Lutjeharms et al., 1989). Even the vertical gradient of the seasonal thermocline over the Agulhas Bank is entirely representative for this time of year (Lutjeharms et al., 1996); although it is slightly less intense than in Fig. 4b. The difference could be explained by diminishing solar heating from March to April and/or excessive vertical numerical diffusion in the model. It results in lower sea surface temperatures for the model than in Fig. 4a. A sea surface temperature of $23^{\circ} \mathrm{C}$ for the core of the Agulhas Current is more typical for this time of the year (Christensen, 1980). One may conclude that the lateral as well as the vertical simulation of shear edge features by the model is encouraging.

Shear edge eddies are also present in winter as can be seen in Fig. 6 for hydrographic data and in Fig. 7 for the model. For this time of the year, the vertical thermal structure is also remarkably well represented by the model, showing a relatively homogeneous water mass $\left(15^{\circ} \mathrm{C}\right)$ on the Agulhas Bank (Figs. 7b and 6b). The distribution of sea surface temperatures shows the warm plume that envelops the shear edge eddy both in the model (Fig. 7a) and in the hydrographic data (Fig. 6a). The plume appears to be further downstream $(100 \mathrm{~km})$ in the hydrographic data than in the model results. Since shear edge features have been observed to propagate westward along the shelf edge, the plume shown in Fig. 6 is in a more advance stage of evolution than the one presented in Fig. 7. At this time of the year, the cold dome happens to be more marked than in summer.

Regrettably there are insufficient data on shear edge features of the Agulhas Current to afford 


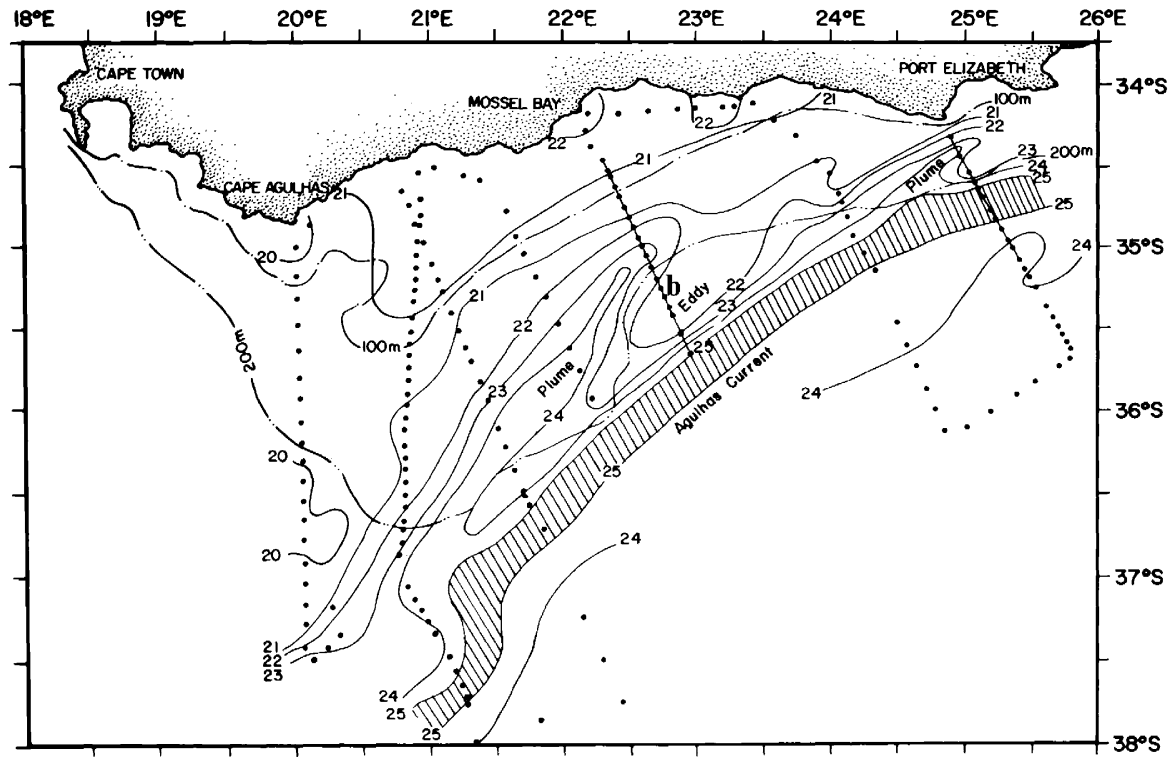

(a)

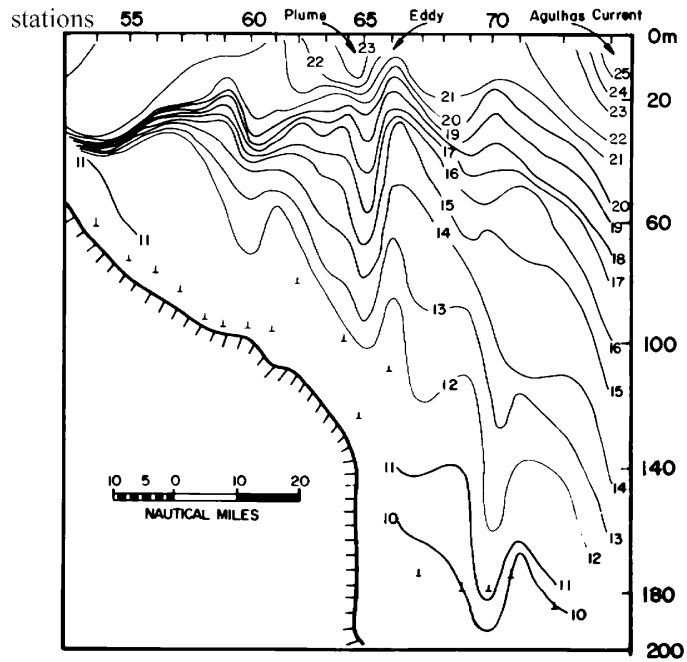

(b)

Fig. 4. (a) Distribution of temperature $\left({ }^{\circ} \mathrm{C}\right.$ ) at $10 \mathrm{~m}$ over the Agulhas Bank in March 1968. (b) Temperature cross section across a shear edge eddy south of Mossel Bay. Adapted from Lutjeharms et al. (1989).

more inter-comparisons between the model simulations and actual observations. Nonetheless, those that have been presented here are such that they give us considerable confidence in the reliability of the model.

\section{Evolution of simulated shear edge eddies}

A modelled time series for the sea surface elevation over the Agulhas Bank and general vicinity is portrayed in Fig. 8 . It is given with 8 
(a) Position of the section

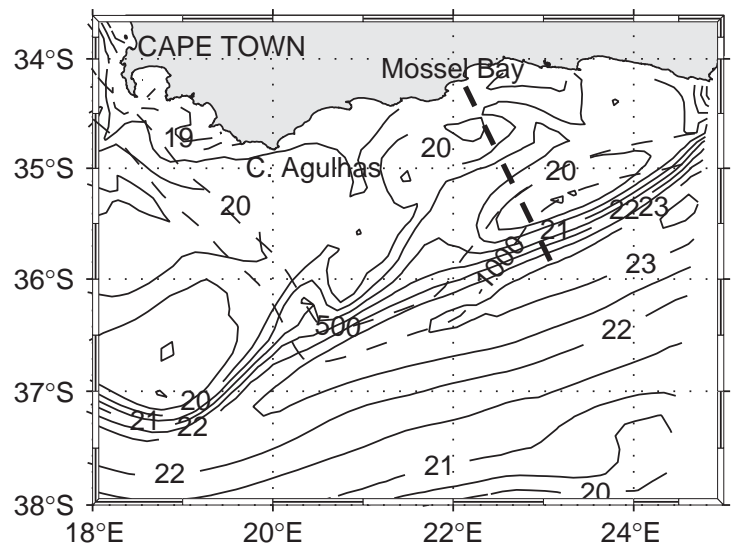

(b) Temperature cross section

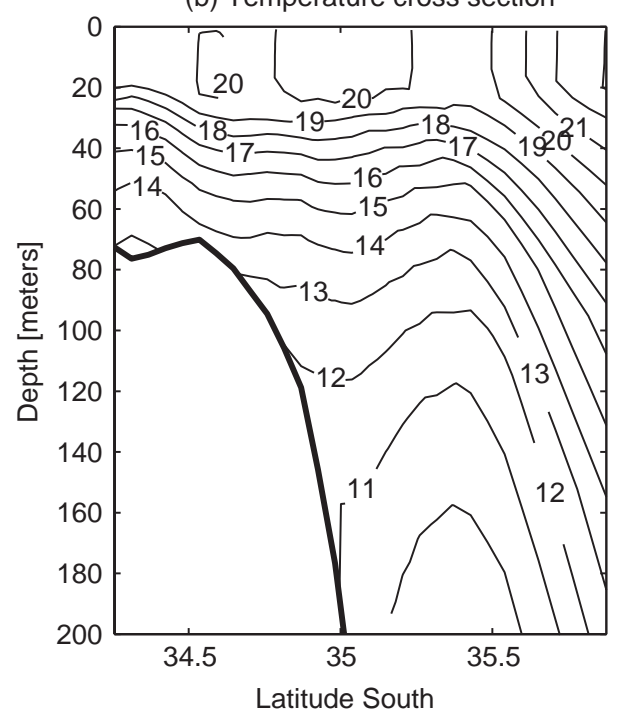

Fig. 5. (a) This panel is identical to that in Fig. 2. The interval between the isolines is $0.5^{\circ} \mathrm{C}$. The broken line indicates the location of a simulated vertical section from the land across the shelf and shelf edge and crossing the edge of the Agulhas Current. The section itself is given in the bottom panel. (b) A vertical temperature section to $200 \mathrm{~m}$ depth along the broken line in the top panel. Note the warm water of the Agulhas Current, the dome of cold water forming a shear eddy and the plume of warm water $\left(\geqslant 20^{\circ} \mathrm{C}\right)$ extending to a depth of $20 \mathrm{~m}$.

day intervals, starting on 7 December of model year 7. In the first image (Fig. 8a) there is a welldeveloped Agulhas Current with a large cyclonic shear eddy in the eastern bight of the edge of the Agulhas Bank. West of the Agulhas Bank there is a weakly developed anti-cyclone, about $250 \mathrm{~km}$ in diameter. The presence of an anti-cyclone in this region has been shown to occur at least $12 \%$ of the time (Lutjeharms and Valentine, 1988). The model also shows a small anti-cyclone in the northeasterly corner of the modeled field over the Agulhas Bank. It remains largely unchanged throughout the sequence. We are unsure if it is an artifact of the boundary conditions. A week later (Fig. 8b), the shear edge eddy has shrunk somewhat in size, having split off a very small eddy that is now moving downstream at about the rate such eddies are known to propagate (Lutjeharms et al., 1989). The anti-cyclonic eddy had grown somewhat in strength. On the next panel these developments continue (Fig. 8c). By 1 January (Fig. 8d) the smaller shear edge eddy has grown in size and has left the eastern shelf edge. The large shear eddy in the bight has again spawned a protrusion, this time considerably bigger.

A week later this protrusion has split of as a slightly larger eddy and is moving downstream as did its predecessor. Its predecessor has by now developed into a strong Agulhas Bank lee eddy, characterized by a sea surface height $25 \mathrm{~cm}$ lower than its South Atlantic environment. Two weeks later (Fig. 8g) the second shear edge eddy had been absorbed into this lee eddy, had strengthened it to a $30 \mathrm{~cm}$ anomaly, and the lee eddy can be seen moving away into the South Atlantic Ocean (Penven et al., 2001; Lutjeharms et al., 2003). Such cyclones have been observed in this region in altimetry (Gründlingh, 1995), from hydrographical measurements (C. Veth, S. Drijfhout, personal communication) and from the tracks of RAFOS floats (Lutjeharms et al., 2003). On the last panel of this sequence (Fig. 8h), the lee eddy has moved totally eastward and the main shear edge eddy is producing another downstream protrusion.

These images are a piecemeal selection from a much more detailed series. This process can therefore be shown with considerably better temporal resolution (Fig. 9). The top panel shows the setting for this region with the thick broken line indicating the path along which the sea surface elevation will be followed (Fig. 9a). In Fig. 9b, the lighter greyscale shows sea surface deepening in comparison to the surroundings, thus cyclonic 


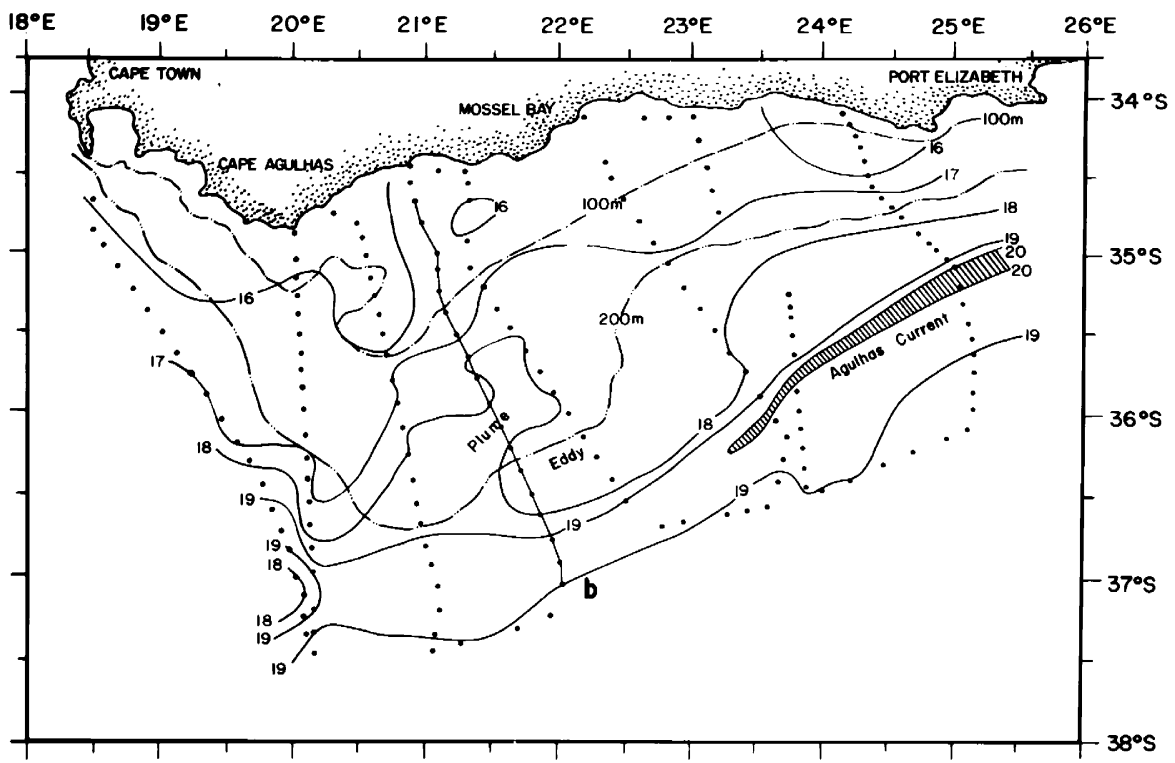

(a)

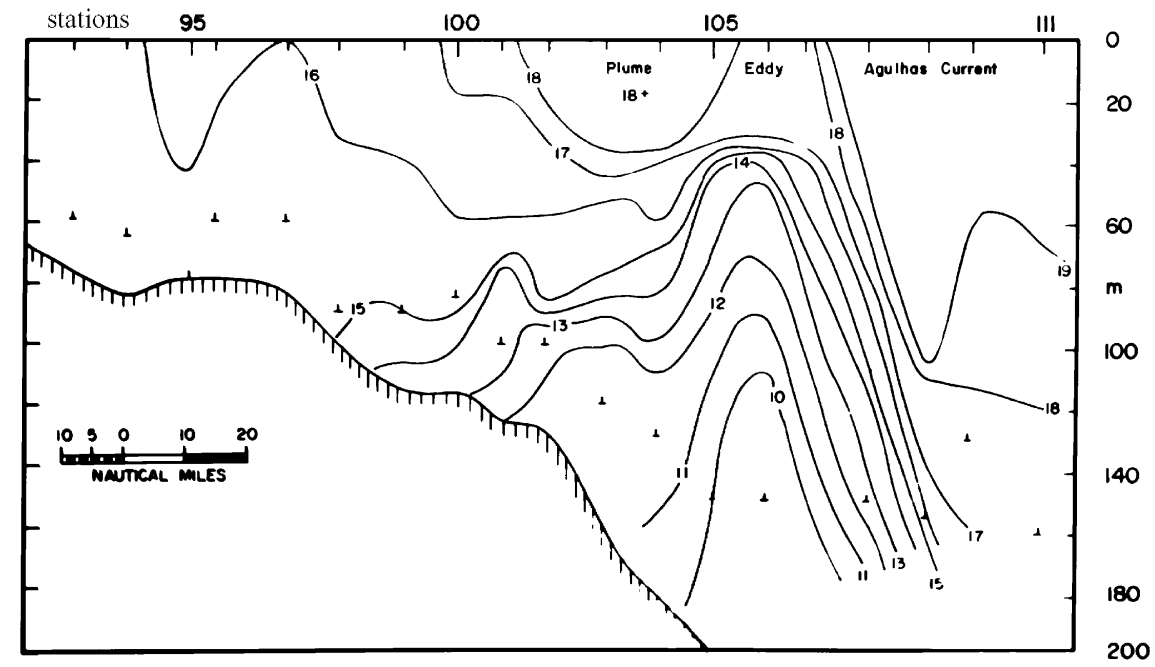

(b)

Fig. 6. (a) Distribution of temperature $\left({ }^{\circ} \mathrm{C}\right)$ at $10 \mathrm{~m}$ over the Agulhas Bank in September 1968. (b) Temperature cross section across a shear edge eddy south of Mossel Bay. Adapted from Lutjeharms et al. (1989).

motion. Hence, the displacement of the cyclonic shear edge eddy and the lee eddy can be followed along the broken line by looking at low sea surface height values. The Hovmüller diagram in the bottom panel (Fig. 9b) thus shows the development over time, starting at the bottom and moving upward. Note that the direction is not the same as in the top panel (Fig. 9a), but has been inverted.

Starting from 1 December of model year 7 (see Fig. 8a) there is a well-developed shear edge eddy at $100 \mathrm{~km}$ and an anticyclone at $500 \mathrm{~km}$, i.e. in the lee of the Agulhas Bank. The subsequent leakage 
(a) Position of the section

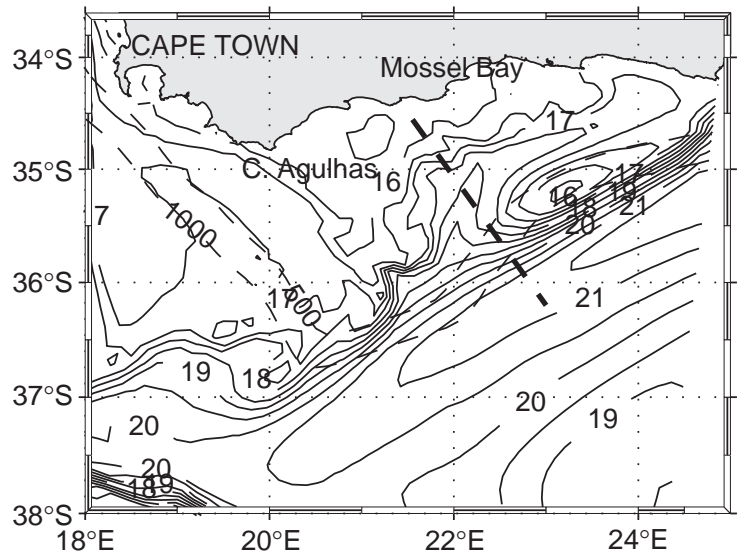

(b) Temperature cross section

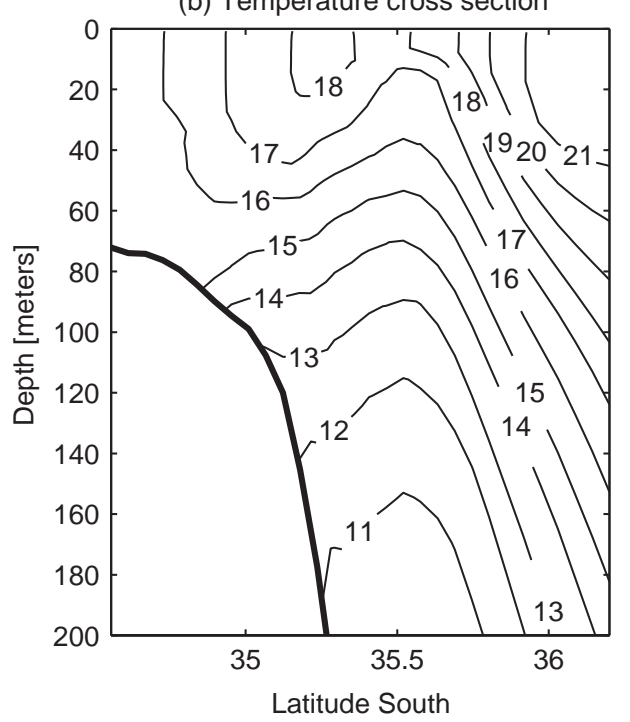

Fig. 7. (a) The sea surface temperature $\left({ }^{\circ} \mathrm{C}\right)$ simulated for 15 September of model year 7. Otherwise as in Fig. 5a. The broken line indicates the location of a simulated vertical section from the land across the shelf and shelf edge an crossing the edge of the Agulhas Current that is given in the bottom panel. (b) Vertical temperature $\left({ }^{\circ} \mathrm{C}\right)$ section to $200 \mathrm{~m}$ along the line.

of cyclonic eddies from the shear edge eddy to the lee of the bank is shown most clearly by the clear track from the left-hand side of the panel to the right-hand side starting on 1 January and ending at $450 \mathrm{~km}$ distance on 20 January. On the first part of its trip, the shear edge eddy travels along the line at approximately $6 \mathrm{~km} \mathrm{day}^{-1}$. On 15 January, at the southern tip of the Agulhas Bank $(x=350 \mathrm{~km})$, it accelerates up to $32 \mathrm{~km} \mathrm{day}^{-1}$. On 20 January, it is absorbed by a larger cyclonic eddy developing in the lee of the Agulhas Bank (Penven et al., 2001). The replacement of an anticyclone by a cyclone in the lee of the Agulhas Bank is represented by the change from dark to clear at $500 \mathrm{~km}$ distance along the line on about 1 January of model year 8 .

These simulations leave one with the impression that it is the Agulhas Current that sequesters the shear edge eddy in the eastern bight of the Agulhas Bank and allows, at almost regular intervals, a certain part of the eddy to escape. The cyclonic vorticity of this propagating eddy may then be taken up by a lee eddy. How does this scenario compare to what has been observed at sea?

Satellite imagery for the region shows that warm plumes, assumed to be associated with shear edge eddies, consistently exhibit a downstream motion. A plume might of course be associated either with an independent, separated eddy or with the leading edge of a protrusion from a shear eddy trapped in the eastern bight. Therefore, both possibilities remain open: there may be distinct eddies moving downstream, or occasional protrusions still attached to a trapped eddy. Statistically, the bight is known for the prevalence of shear edge eddies (Lutjeharms et al., 1989) so that the concept of a near-stationary, but leaky, eddy at this location is not inconsistent with the data. However, with very limited data it cannot be confirmed in a rigorous manner at present. If this single simulation of the evolution of shear edge eddies at the Agulhas Current edge seems reasonably sound, how representative is it of other such sequences in the model?

\section{Interannual variation in simulated eddy evolution}

The simulated behavior of shear edge eddies along the edge of the Agulhas Bank for a 6-year period in the model run is presented in Fig. 10. Except for the more prolonged period, the portrayal is identical to that of Fig. 9b. The sea surface height is tracked along the line used in Fig. 9b. A number of notable features are 


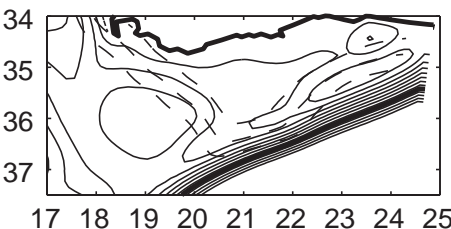

(a)

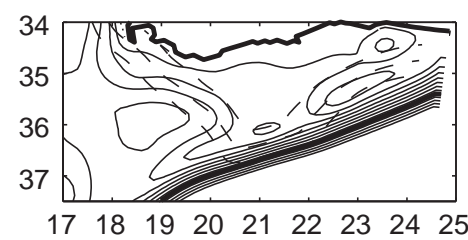

(c)

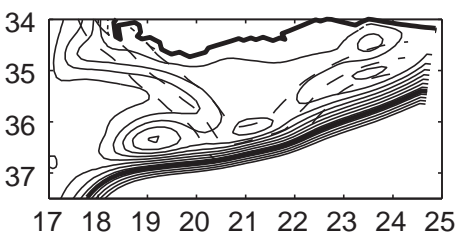

(e)

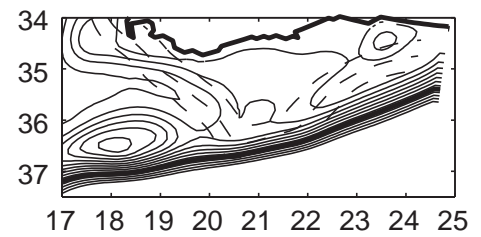

(g)

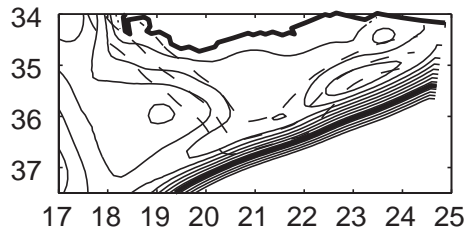

(b)

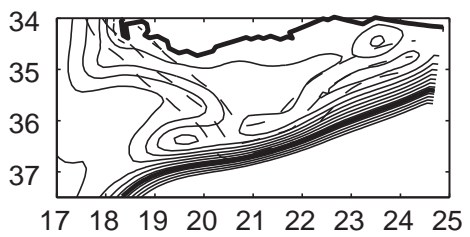

(d)

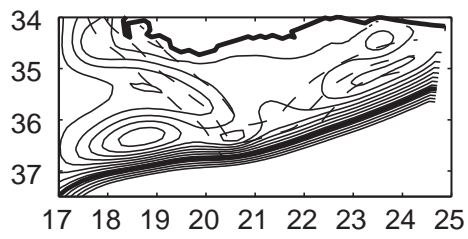

(f)

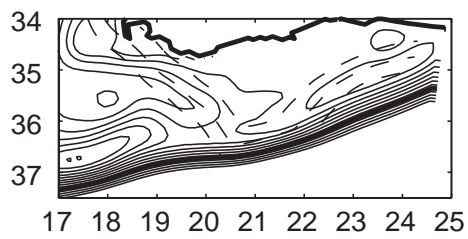

(h)

Fig. 8. The simulated evolution of shear edge eddies along the eastern side of the Agulhas Bank. The broken lines denote the 200,500 and $1000 \mathrm{~m}$ isobaths. The sea surface height is shown (contour lines from -60 to $20 \mathrm{~cm}$, the latter being the value south of the Agulhas Current). The interval between the isocontours is $5 \mathrm{~cm}$. The bold line is the $0 \mathrm{~cm}$ isocontour. The dates are (a) 7 December of model year 7, (b) 15 December of model year 7, (c) 23 December of model year 7, (d) 1 January of model year 8, (e) 7 January of model year 8, (f) 15 January of model year 8, (g) 23 January of model year 8 and (h) 1 February of model year 8.

immediately apparent. First, there are considerable inter-annual and intra-annual variations. Since the surface and lateral boundary conditions are respectively monthly and seasonal climatologies, this variability is solely generated by the internal physics of the model itself.

In this depiction, the center of the trapped shear eddy is located at a distance of $100 \mathrm{~km}$ in Fig. 10. This location seems to be relatively invariant, but the dimensions and intensity of the eddy varies considerably with time. There are events lasting about 6 weeks when it is particularly welldeveloped (e.g. November year 5 and February year 6, Fig. 10b), and longer periods when is seems very weak or totally absent (e.g. December year 6 to February year 7 and June year 7 to August year 7, Figs. 10b and c). The absence of a trapped shear eddy seems to coincide with large offshore displacements of the Agulhas Current. This large scale movements of the current is reflected by the appearance of sea surface height elevations at a distance of about $300 \mathrm{~km}$ along the track and a 
(a) Position of the track line
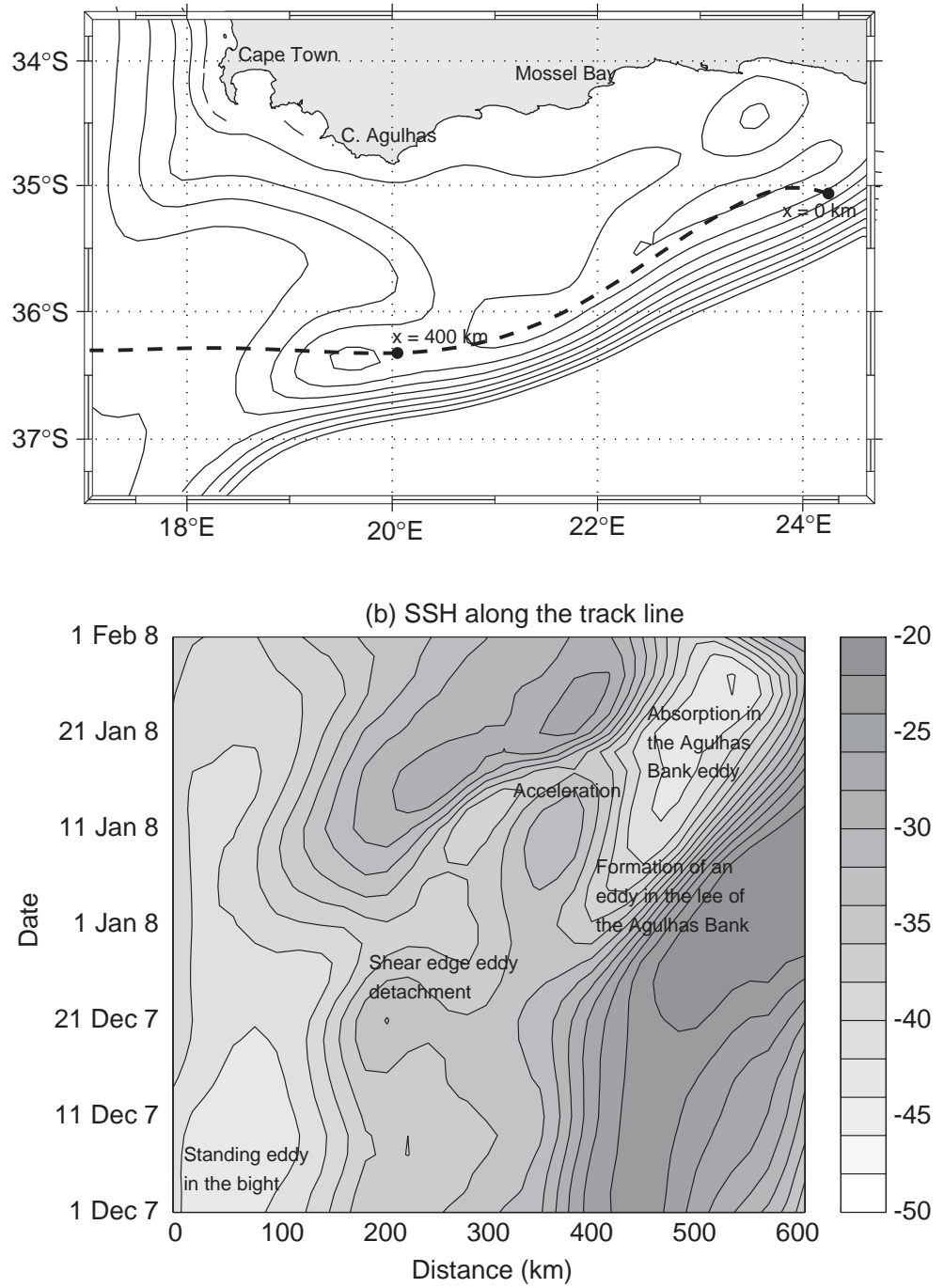

Fig. 9. Tracking the westward leakage of cyclonic vorticity from the shear edge feature in the form of a bud-off eddy. The top panel (a) depicts the sea surface height for 1 January of year 8 ( $5 \mathrm{~cm}$ between the isocontours). Note the cores of the shear edge eddy between $23^{\circ} \mathrm{E}$ and $24^{\circ} \mathrm{E}$ and the Agulhas Bank lee eddy between $18^{\circ} \mathrm{E}$ and $19^{\circ} \mathrm{E}$. The broken line is used to track the movement of water with a cyclonic motion (i.e. low sea surface height). The Hovmüller diagram on the bottom panel (b) shows the movement in time (increasing upward on the ordinate). The distance on the abscissa is from the easternmost point on the solid line in the upper panel, i.e. $x=0$ is at $24.25^{\circ} \mathrm{E}$ and $35^{\circ} \mathrm{S}$; the distances on the abscissa are positive traveling westward. The interval between the isocontours is $2 \mathrm{~cm}$.

simultaneous sea level enhancement in the far eastern part of the domain (left side of columns in Fig. 10). At the westernmost part of the field (right side of columns in Fig. 10) marked positive and negative departures from the mean sea surface height show the spasmodic exchange of cyclonic and anticyclonic motion. This may be interpreted as the replacement of a northward meander in the simulated Agulhas Current with a cyclonic lee eddy (e.g. April year 3, Fig. 10a).

Perhaps of most interest is the clear signs of intermittent, but frequent, leakage of cyclonic motion from the upstream region to the downstream region in the model. These are shown as 


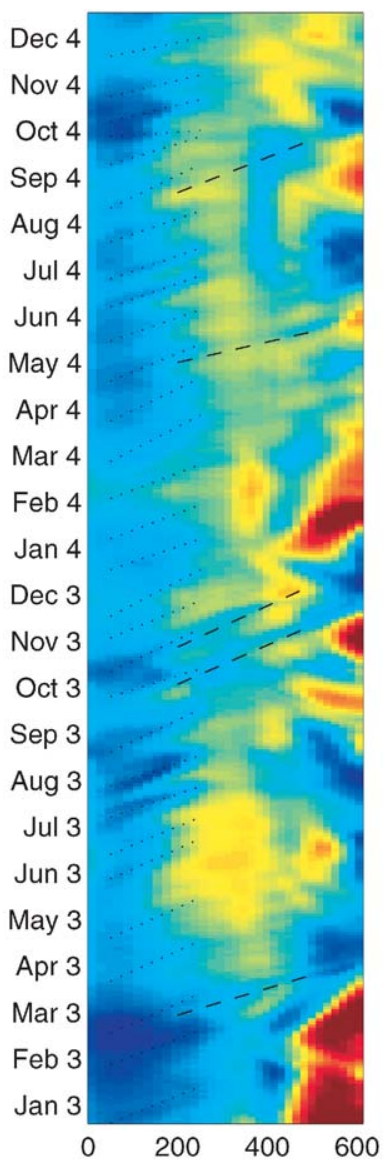

(a) Distance $(\mathrm{km})$

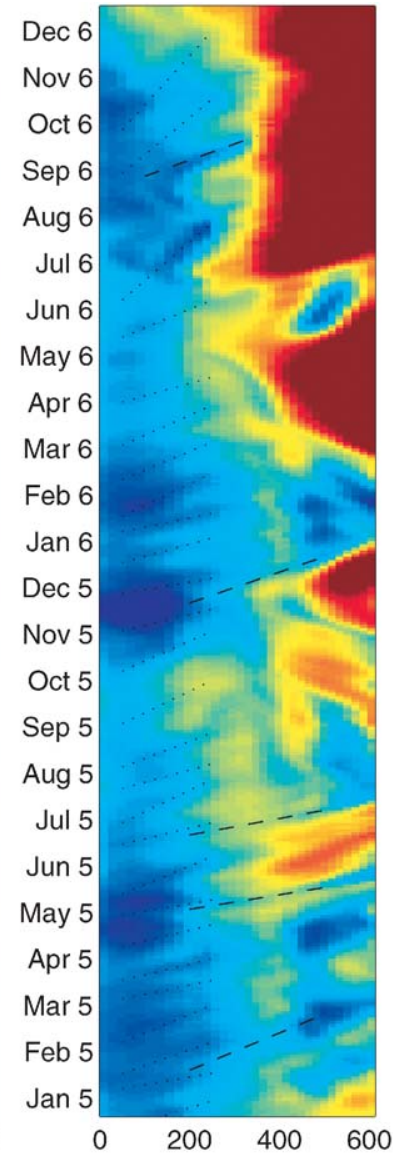

(b) Distance $(\mathrm{km})$

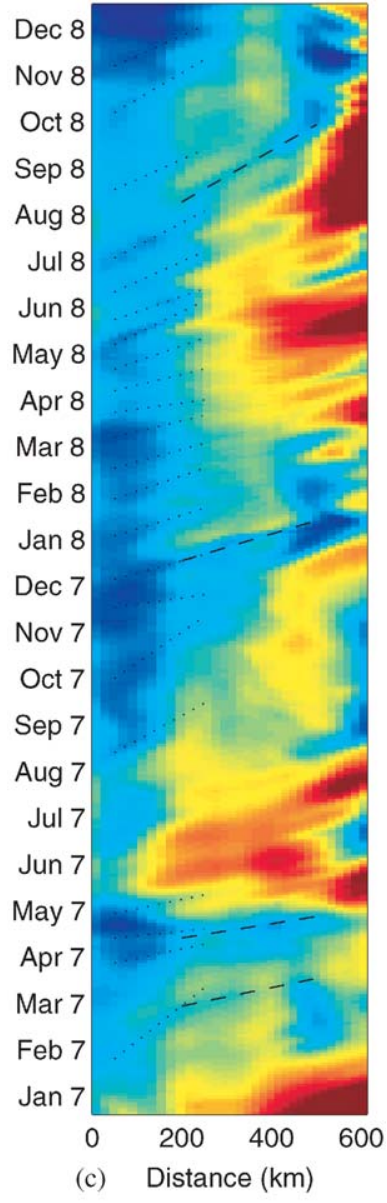

(c) Distance $(\mathrm{km})$

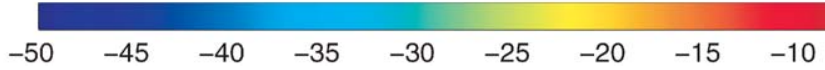

Fig. 10. Hovmüller diagrams of the temporal behavior of modelled circulatory features along the Agulhas Bank. The sea surface elevation $(\mathrm{cm})$ is tracked along the line defined on Fig. 9a. The left panel (a) represents model years 3 to 4 , the central panel (b) years 5 to 6 and the right hand panel (c) years 7 to 8 . Otherwise the images are identical to that of the lower panel of Fig. 9. The lines demonstrate the leakage of cyclonic eddies from the bight.

feint clear lines from left to right in the columns of Fig. 10 and are indicated by dashed lines. Marked eddy leakage can be observed on March year 3, October year 3, November year 3, May year 4, September year 4, February year 5, May year 5, July year 5, December year 5, September year 6, March year 7, April year 7, December year 7 and September year 8 . These lines indicate that the eddies that carry cyclonic motion downstream propagate at roughly $8-12 \mathrm{~km} \mathrm{day}^{-1}$, very close to estimates made from satellite imagery (Harris et al.,
1978; Lutjeharms et al., 1989) for shear edge eddy progression and even for the movement of Natal Pulses along the Agulhas Bank (Lutjeharms and Roberts, 1988; Van Leeuwen et al., 2000). The frequency with which there is a movement downstream from the trapped shear eddy seems to have some regularity if not affected by the large scale movement of the Agulhas Current (e.g. March to November of year 4; Fig. 10a). The spawning of a traveling eddy seems to occur at intervals of roughly 20-30 days in the model with no clear 
seasonal variations in the frequency. Observations in nature to date are insufficient to validate this, mostly due to interference with the satellite thermal infrared measurements by cloud cover. However, indications are of a considerably more irregular process.

\section{Discussion}

A particularity of the actual model solution is the strong indication that a cyclonic eddy may on occasion be trapped in the eastern bight of the Agulhas Bank and is controlled by interactions between the Agulhas Current and the topography. The bight that lies on the eastern side of the Agulhas Bank around $23^{\circ} \mathrm{E}$ is characterized by a bend towards the shore of the $500 \mathrm{~m}$ isobath, the isobaths deeper than $1500 \mathrm{~m}$ running quasi rectilinearly south-westward. This creates an embayment of about $200 \mathrm{~km}$ long and $100 \mathrm{~km}$ wide.

Miller and Lee (1995a) have produced simulated Gulf Stream frontal eddies using a primitive equation model in an idealistic configuration where topography had no along shore variations. Due to a mixture of baroclinic and barotropic instabilities, perturbations produced meanders and eddies. Vertical advection of momentum and frictional dissipation have been found important for the process; and upwelling was pronounced on the leading edge of the features (Miller and Lee, 1995b). These results are consistent with the experiments of Oey (1988). In a two layer model setup, he has reproduced these eddies and their adjacent warm plumes. He has shown that two parameters control the dynamics of the process: the ratio of depth of the upper layer divided by the total water column depth $\left(h / H_{0}\right)$ and the ratio of the distance of the front from the slope divided by the internal Rossby radius of deformation $(L / R)$; the growth being, in this case, predominantly baroclinic. In our simulation, when the Agulhas current overshoot the eastern bight of the Agulhas Bank, the distance ranges from about 20 to $100 \mathrm{~km}$ (Fig. 2); the internal Rossby radius being measured at $35 \mathrm{~km}, L / R$ is ranging from 0.5 to 3 . A reasonable value for $h / H_{0}$ for the Agulhas Current being $\frac{1}{3}$, following Oey (1988), the regime is expected to be relatively stable upstream of the bight, more unstable in the bight, and again more stable at the tip of the Bank. Although this does not explain the presence of the trapped eddy, it is not in disagreement with our model results. Oey's experiments have also shown that the speeds of eddy propagation increased with diminishing $L / R$. This is also observed in our simulation when shear eddies reach the southern tip of the Agulhas Bank (Fig. 9).

To simulate the fate of a western boundary current over a continental slope, Lee et al. (2001) have coupled the Stommel and the Munk boundary layer models to the arrested topographic wave model (Csanady, 1978). While the steepness of the slope in this case plays an important role in determining the structure of the current, this model did not reveal the effect of bottom friction on border phenomena. The arrested topographic wave model has also been adapted by Hetland et al. (2001) to comprehend the effect of bottom friction on the dissipation of a northward propagating jet along the west Florida shelf. The decay of the current is here induced by a cross-shore flow that feeds a counter-current onto the shelf. Whereas this setup is opposite (in the sense of coastal wave propagations) to our problem, it illustrates a possible process able to generate a reverse flow onto the shelf by interactions between bottom friction and the continental shelf slope. A reverse flow is also observed for the mean surface currents in our simulation (Fig. 1). This could be a reason for the development of reverse plumes.

An attractive explanation for eddy trapping by an embayment can be found in Johnson and Clarke (2001). In their review on Rossby wave hydraulics, they present a flow hydraulically controlled by topographic Rossby waves at a minimum of the shelf width. In the case of the condition for a supercritical leap between a pair of supercritical flows in the upstream and downstream branches, a large cyclonic recirculation region at the shelf narrowing is generated. The idea of an hydraulic control of the current at a minimum of the shelf width has been exploited by Gill and Schumann (1979). Using a two-layers, semi-geostrophic model that preserves the potential vorticity of the current, they show that a 
reversed flow can occur upstream of the minimum and an outcropping of cold water downstream.

These findings consolidate the idea that an eddy can remain trapped in the Agulhas Bank bight. In our model, the Agulhas Current is forced by the inflow condition at the eastern lateral open boundary. Since it is forced by cyclic seasonal, time-averaged data, no interannual variations and no eddy variability is injected from the boundary. Topography, which is a key for shear edge eddies evolution, has been smoothed to prevent errors in the pressure gradient. Both elements can affect the realism of the solution.

Measurements of primary productivity and nitrogen uptake on the eastern Agulhas Bank have revealed a higher level of primary productivity than in other western boundary current systems (Probyn et al., 1995). Strong enhancement of biological productivity by frontal eddies has also been demonstrated for the Gulf Stream (Lee et al., 1981), the Kuroshio (Kimura et al., 1997), and the East Australian Current (Marchesiello and Middleton, 2000). In the case of the Agulhas Current, the maximum of productivity lies exactly in the eastern bight of the Agulhas Bank, showing an exceptionally large value for production, normalized to biomass. A nutrient supply from the deeper waters is required to maintain the primary productivity at the measured rate. The vertical motions associated with the recirculation in the bight might give a possible process for the water column enrichment. The recirculation could also help the aggregation of the biogeochemical components. These hypothesis should be verified by coupling the model to a biological module and by verifying the model results by directed and appropriate observations at sea.

\section{Conclusion}

The model described here, simulates the creation of cyclonic shear edge eddies and their attendant surface plumes of warm water with a high degree of verisimilitude. The dimensions of the features, their hydrographic structure and their velocities in the model bear a strong resemblance to what has been observed.
The model suggests that a shear edge eddy may remain trapped in the bight on the eastern side of the shelf break of the Agulhas Bank and that eddies that travel downstream represent leakages from this resident shear eddy. This is not inconsistent with observations to date, but cannot be unambiguously verified. Although the current axis shows some degree of meandering in the model, this is much less than in nature, suggesting that much larger parts — or even the full — trapped eddy might occasionally escape and move downstream.

Once they reach the southernmost tip of the Agulhas Bank, the traveling eddies in the model may be absorbed by a cyclonic eddy in the western lee of the bank or may initiate the formation of such an eddy. The model does not indicate unequivocally whether such absorption has an effect on the timing of the eastward departure of the lee eddy.

We look forward to these intriguing model conclusions being tested by judicious placements of current moorings along the Agulhas Bank.

\section{Acknowledgements}

Funding for this work was provided by the South African French VIBES/IDYLE project, by the National Research Foundation of South Africa, by the University of Cape Town and by the "Département des Ressources Vivantes" of the IRD (France). This is a contribution to GLOBECSPACC. Thanks to J.C. McWilliams.

\section{References}

Biastoch, A., Krauß, W., 1999. The role of mesoscale eddies in the source regions of the Agulhas Current. Journal of Physical Oceanography 29, 2303-2317.

Boyd, A.J., Oberholster, G.P.J., 1994. Currents off the West and South coasts of South Africa. SA Shipping News \& Fishing Industry Review, 26-28.

Boyd, A.J., Shillington, F.A., 1994. Physical forcing and circulation patterns on the Agulhas Bank. South African Journal of Science 90, 114-122.

Christensen, M.S., 1980. Sea-surface temperature charts for Southern Africa, south of $26^{\circ} \mathrm{S}$. South African Journal of Science 76, 541-546. 
Csanady, G.T., 1978. The arrested topographic wave. Journal of Physical Oceanography 8, 47-62.

Da Silva, A.M., Young, C.C., Levitus, S., 1994. Atlas of surface marine data 1994, Vol. 1, algorithms and procedures. NOAA Atlas NESDIS 6, US Department of Commerce, NOAA, NESDIS, USA, 74pp.

De Ruijter, W.P.M., van Leeuwen, P.J., Lutjeharms, J.R.E., 1999. Generation and evolution of Natal Pulses: solitary meanders in the Agulhas Current. Journal of Physical Oceanography 29, 3043-3055.

Flather, R.A., 1976. A tidal model of the northwest European continental shelf. Mémoires de la Société Royale des Sciences de Liège 10, 141-164.

Gill, A.E., Schumann, E.H., 1979. Topographically induced changes in the structure of an inertial coastal jet: application to the Agulhas Current. Journal of Physical Oceanography 9, 975-991.

Goschen, W.S., Schumann, E.H., 1990. Agulhas Current variability and inshore structures off the Cape Province, South Africa. Journal of Geophysical Research 95, 667-678.

Goschen, W.S., Schumann, E.H., 1994. An Agulhas Current intrusion into Algoa bay during August 1988. South African Journal of Marine Science 14, 47-57.

Gründlingh, M.L., 1979. Observation of a large meander in the Agulhas Current. Journal of Geophysical Research 84, 3776-3778.

Gründlingh, M.L., 1983. On the course of the Agulhas Current. South African Geographic Journal 65, 49-57.

Gründlingh, M.L., 1995. Tracking eddies in the southeast Atlantic and southwest Indian oceans with TOPEX/ POSEIDON. Journal of Geophysical Research 100, 24977-24986.

Gründlingh, M.L., Pearce, A.F., 1990. Frontal features of the Agulhas Current in the Natal Bight. South African Geographic Journal 72, 11-14.

Haidvogel, D.B., Arango, H., Hestrom, K., Beckmann, A., Malanotte-Rizzoli, P., Shchepetkin, A., 2000. Model evaluation experiments in the North Atlantic basin: simulations in nonlinear terrain-following coordinates. Dynamics of Atmospheres and Oceans 32, 239-381.

Harris, T.F.W., Legeckis, R., van Foreest, D., 1978. Satellite infra-red images in the Agulhas Current system. Deep-Sea Research 25, 543-548.

Hetland, R., Hsueh, Y., Yuan, D., 2001. On the decay of a baroclinic jet flowing along a continental slope. Journal of Geophysical Research 106, 19,797-19,807.

Johnson, R., Clarke, S.R., 2001. Rossby wave hydraulics. Annual Reviews in Fluid Mechanics 33, 207-230.

Kimura, S., Kasai, A., Nakata, H., Sugimoto, T., Simpson, J.H., Cheok, J.V.S., 1997. Biological productivity of mesoscale eddies caused by frontal disturbances in the Kuroshio. ICES Journal of Marine Science 54, 179-192.

Large, W.G., McWilliams, J.C., Doney, S.C., 1994. Oceanic vertical mixing: a review and a model with a nonlocal boundary layer parameterization. Reviews in Geophysics 32, 363-403.
Lee, S.-K., Pelegrí, J.L., Kroll, J., 2001. Slope control in western boundary currents. Journal of Physical Oceanography 31, 3349-3360.

Lee, T., Atkinson, L., Legeckis, R., 1981. Observations of a Gulf Stream frontal eddy on the Georgia continental shelf, April 1977. Deep-Sea Research 28, 347-378.

Lutjeharms, J.R.E., 1981. Features of the southern Agulhas Current circulation from satellite remote sensing. South African Journal of Science 77, 231-236.

Lutjeharms, J.R.E., 1996. The exchange of water between the South Indian and the South Atlantic. In: Wefer, G., Berger, W.H., Siedler, G., Webb, D. (Eds.), The South Atlantic: Present and Past Circulation. Springer, Berlin, pp. 125-162.

Lutjeharms, J.R.E., Cooper, J., 1996. Interbasin leakage through Agulhas Current filaments. Deep-Sea Research Part I 43, 213-238.

Lutjeharms, J.R.E., Roberts, H.R., 1988. The Natal pulse; an extreme transient on the Agulhas Current. Journal of Geophysical Research 93, 631-645.

Lutjeharms, J.R.E., Valentine, H.R., 1988. Evidence for persistent Agulhas rings south-west of Cape Town. South African Journal of Science 84, 781-783.

Lutjeharms, J.R.E., van Ballegooyen, R.C., 1988. The retroflection of the Agulhas Current. Journal of Physical Oceanography 18, 1570-1583.

Lutjeharms, J.R.E., Catzel, R., Valentine, H.R., 1989. Eddies and other border phenomena of the Agulhas Current. Continental Shelf Research 9, 597-616.

Lutjeharms, J.R.E., Meyer, A.A., Ansorge, I.J., Eagle, G.A., Orren, M.J., 1996. The nutrient characteristics of the Agulhas Bank. South African Journal of Marine Science 17, 253-274.

Lutjeharms, J.R.E., Boebel, O., Rossby, H.T., 2003. Agulhas cyclones. Deep-Sea Research Part II 50, 13-34.

Marchesiello, P., Middleton, J.H., 2000. Modeling the East Australian Current in the western Tasman Sea. Journal of Physical Oceanography 30, 2956-2971.

Marchesiello, P., McWilliams, J.C., Shchepetkin, A., 2001. Open boundary condition for long-term integration of regional oceanic models. Ocean Modelling 3, 1-21.

Miller, J.L., Lee, T.N., 1995a. Gulf Stream meanders in the South Atlantic Bight, 1, Scaling and energetics. Journal of Geophysical Research 100, 6687-6704.

Miller, J.L., Lee, T.N., 1995b. Gulf Stream meanders in the South Atlantic Bight, 2, Momentum balances. Journal of Geophysical Research 100, 6705-6724.

Oey, L.-Y., 1988. A model of Gulf Stream frontal instabilities, meanders and eddies along the continental slope. Journal of Physical Oceanography 18, 211-229.

Penven, P., Lutjeharms, J.R.E., Marchesiello, P., Roy, C., Weeks, S.J., 2001. Generation of cyclonic eddies by the Agulhas Current in the lee of the Agulhas Bank. Geophysical Research Letters 27, 1055-1058.

Probyn, T.A., Mitchell-Innes, B.A., Searson, S., 1995. Primary productivity and nitrogen uptake in the subsurface chlorophyll maximum on the Eastern Agulhas Bank. Continental Shelf Research 15, 1903-1920. 
Schumann, E.H., Beekman, L.J., 1984. Ocean temperature structures on the Agulhas Bank. Transactions of the Royal Society of South Africa 45, 191-203.

Schumann, E.H., Perrins, L.-A., 1982. Tidal and inertial currents around South Africa. In: Proceedings of the Eighteenth International Coastal Engineering Conference, American Society of Civil Engineers, Cape Town, South Africa, pp. 2562-2580.

Schumann, E.H., van Heerden, I.L., 1988. Observations of Agulhas Current frontal features south of Africa. Deep Sea Research Part A 35, 1355-1362.

Shchepetkin, A.F., McWilliams, J.C., 1998. Quasi-monotone advection schemes based on explicit locally adaptive dissipation. Monthly Weather Review 126, 1541-1580.
Shchepetkin, A.F., McWilliams, J.C., unpublished. Regional Ocean Model System: a split-explicit ocean model with a free-surface and topography-following vertical coordinate, UCLA, Los Angeles, USA.

Smith, W.H.F., Sandwell, D.T., 1997. Global seafloor topography from satellite altimetry and ship depth soundings. Science 277, 1957-1962.

Swart, V.P., Largier, J.L., 1987. Thermal structure of Agulhas Bank water. South African Journal of Marine Science 5, 243-253.

Van Leeuwen, P.J., de Ruijter, W.P.M., Lutjeharms, J.R.E., 2000. Natal Pulses and the formation of Agulhas rings. Journal of Geophysical Research 105, 6425-6436. 